\title{
Outline of Europe-Japan Collaborative Research on Concentrator Photovoltaics
}

\author{
Masafumi Yamaguchi and Antonio Luque
}

\begin{abstract}
The Europe-Japan Collaborative Research Project on Concentrator Photovoltaics (CPV) has been initiated under support by the EC (European Commission) and NEDO (New Energy and Industrial Technology Development Organization) since June 2011. This is project (NGCPV Project; a New Generation of Concentrator PhotoVoltaic cells, modules and systems ) is aiming to accelerate the move to very high efficiency and lower cost CPV technologies and to enhance widespread deployment of CPV systems. 7 organizations such as UPM, FhGISE Imperial College, BSQ, CEA-INES, ENEA, and PSE in Europe and 9 organizations such as TTI, Univ. Tokyo, AIST, Sharp Co. Daido Steel Co., Kobe Univ., Miyazaki Univ., Asahi Kasei Co., and Takano Co. participate in this project. The targets of this project are 1) to develop world-record efficiency CPV cells of more than $45 \%, 2$ ) to develop world-record efficiency CPV modules of $35 \%, 3$ ) to establish standard measurements of CPV cells and modules, 4) to install 50kW CPV system in Spain, to carry out field test of CPV system and to manage power generation of CPV systems, and 5) to develop high-efficiency and low-cost new materials and structure cells such as III-V-N, III-Von-Si tandem, quantum dots and wells. This paper presents outline of this project and most recent results such as world record efficiency (37.9\% under 1-sun) cell and high-efficiency (43.5\% under 240-306 suns) concentrator cell with inverted epitaxial grown InGaP/GaAs/InGaAs 3-junction solar cells.
\end{abstract}

Index Terms - III-V compounds, multi-junction solar cells, concentrator cells, modules and systems, epitaxy, defect analysis

\section{INTRODUCTION}

Figure 1 shows efficiency status and limitations of various types of single-junction solar cells. Although $25 \%$ and $28.8 \%$ efficiencies have been attained with single crystalline $\mathrm{Si}$ and GaAs single-junction solar cells [1], efficiency limitations for single-junction solar cells are thought to be around $30 \%$ III-V compound multi-junction and concentrator solar cells have great potential of more than $50 \%$ [2], because $44 \%$ and $44.4 \%$ efficiencies have been already been demonstrated with $\mathrm{InGaP} / \mathrm{GaAs} / \mathrm{InGaAsNSb}$ 3-junction solar cell [3] and InGaP/GaAs/InGaAs 3-junction solar cell [4]. Therefore, concentrator photovoltaics are expected as one of high performance, low-cost and large-scale PV systems.

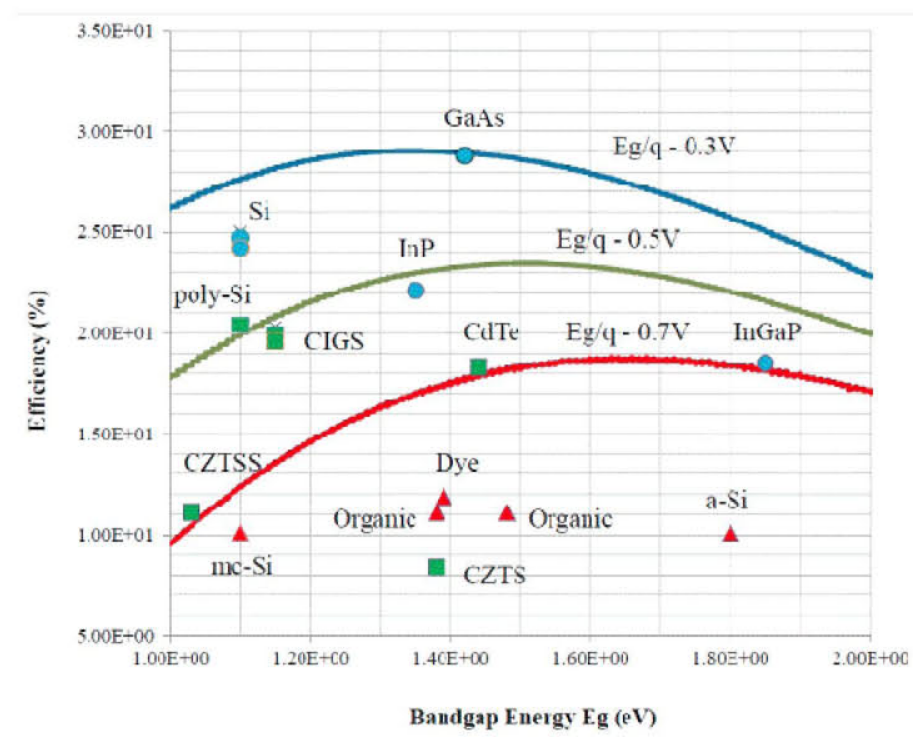

Fig. 1. Efficiency status and limitations of various types of single-junction solar cells.
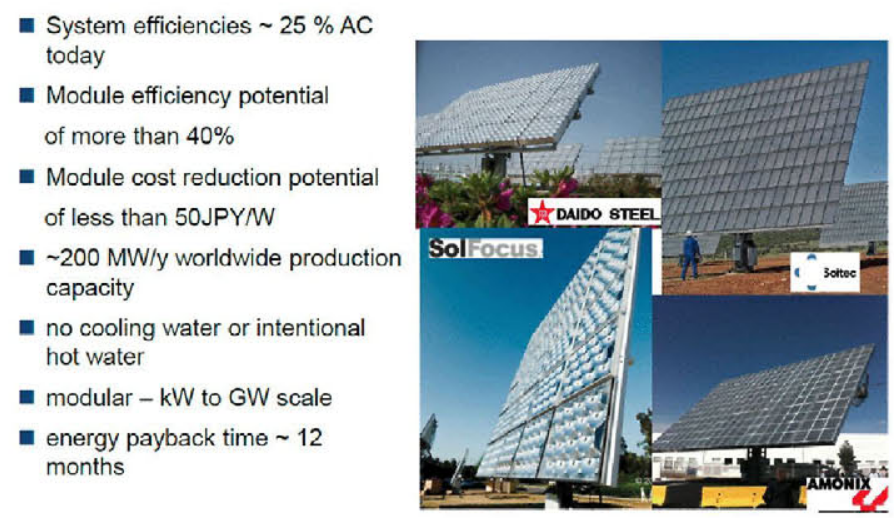

Fig. 2. Advantages of high concentrator photovoltaics.

The Europe-Japan Collaborative Research Project on Concentrator Photovoltaics (CPV) has been initiated under support by the EC (European Commission) and NEDO (New Energy and Industrial Technology Development Organization) since June 2011. Because high concentration PV has great potential of higher efficiency and lower cost [5.6] compared to conventional crystalline Si PV and thin-film PV as shown in Fig.2, CPV has been selected as the EU-Japan collaborative 
research theme. The aim of this project is to accelerate CPV technology development and to promote very large scale deployment of CPV. The authors serve as leaders of Japanese and European teams. 7 0rganizations such as UPM, FhG-ISE Imperial College, BSQ, CEA-INES, ENEA, and PSE in Europe and 9 organizations such as TTI, Univ. Tokyo, AIST, Sharp Co. Daido Steel Co., Kobe Univ., Miyazaki Univ., Asahi Kasei Co., and Takano Co. participate in this project as shown in Fig.3.

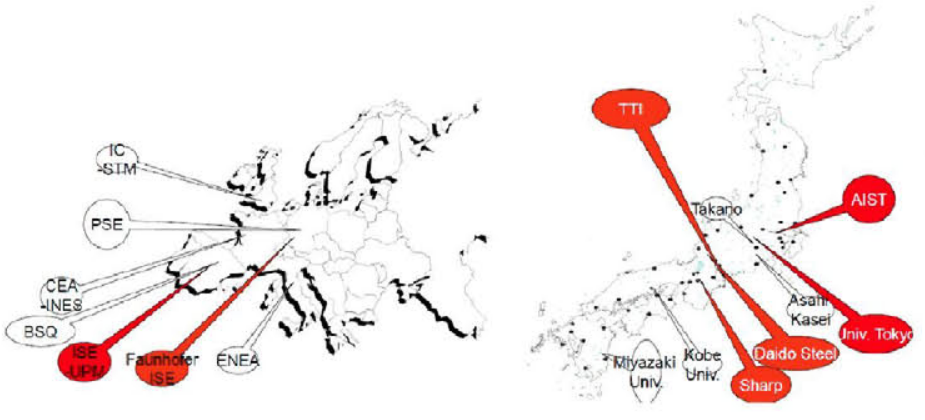

Strong Consortium of Universities, Research Institutes, SMEs and Industry!

Work package leaders are marked in red.

Fig. 3. Partners (7 European and 9 Japanese partners) under the Europe-Japan Collaborative Research on CPV.

\section{Acceleration of CPV R\&D by EU-JPN NG-CPV Project}

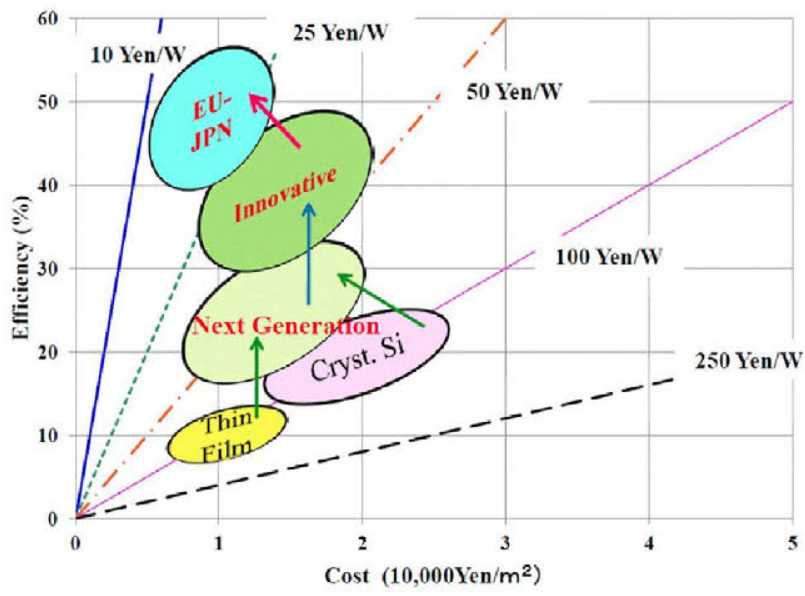

Fig. 4. High efficiency and low-cost targets of NEDO PV R\&D Projects.

The targets of this project are 1) to develop world-record efficiency CPV cells of more than $45 \%, 2$ ) to develop worldrecord efficiency CPV modules of $35 \%$, 3) to establish standard measurements of CPV cells and modules, 4) to install $50 \mathrm{~kW}$ CPV system in Spain, to carry out field test of CPV system and to manage power generation of CPV systems, and 5) to develop high-efficiency and low-cost new materials and structure cells such as III-V-N, III-V-on-Si tandem, quantum dots and wells. This project (NGCPV Project; a New Generation of Concentrator PhotoVoltaic cells, modules and systems ) is aiming to accelerate the move to very high efficiency and lower cost CPV technologies and to enhance widespread deployment of CPV systems, as shown in Fig. 4.

This paper present outline of the NGCPV project and most recent results under the NGCPV project.

\section{RECENT RESULTS}

Figure 5 shows structures and efficiency potential of next generation super high-efficiency III-V compound multijunction solar cells [7]. Lattice-mismatched InGaP/GaAs/InGaAs 3-junction solar cells and lattice-matched InGaP/InGaAs/InGaAsN/Ge 4-junction solar cells have great potential for high efficiency of more than $45 \%$. In this project, high efficiency studies on lattice-mismatched InGaP/GaAs/InGaAs 3-junction solar cells and some fundamental studies on lattice-matched InGaP/InGaAs/InGaAsN/Ge 4-junction solar cells are being carried out.

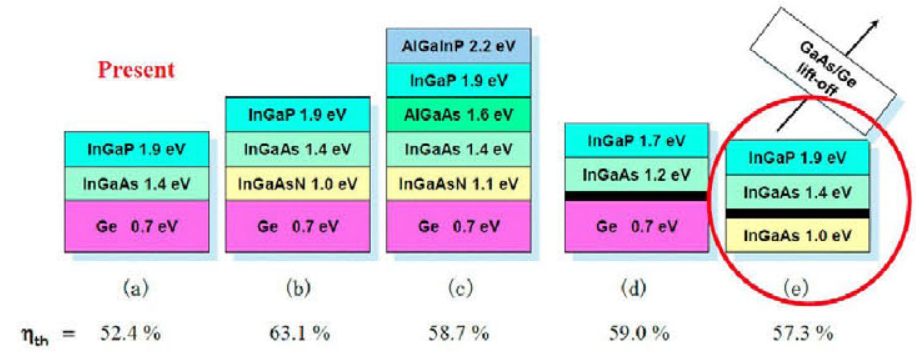

Fig. 5. Structures and efficiency potential of next generation super high-efficiency III-V compound multi-junction solar cells.

Under this project, world-record efficiency inverted epitaxially grown lattice-mismatched $\mathrm{InGaP} / \mathrm{GaAs} / \mathrm{InGaAs} 3$ junction cells with efficiencies of $37.9 \%$ under 1 -sun and $43.5 \%$ under $240-305$-suns has been demonstrated by Sharp Co. [8]. Most, recently, $44.4 \%$ efficiency has been achieved with $\mathrm{InGaP} / \mathrm{GaAs} / \mathrm{InGaAs} 3$-junction solar cell under around 300-suns by Sharp. Co. [4].

In order to realize high efficiency lattice-mismatched InGaP/GaAs/InGaAs 3-junction solar cells, fundamental studies on buffer layer introduction [9], thermal cycle annealing [5], in-situ measurements [10] for strain relaxation and dislocation behavior in lattice-mismatched materials have been carried out. In order to realize high quality relaxed lattice-mismatched layers on GaAs or Ge substrates for super high-efficiency multi-junction solar cells, correlation between strain relaxation and dislocation behavior has been investigated. 
Figure 6 shows photograph and schematic illustration of MBE-XRD measurement system at beam-line 11XU of Spring-8. By using MBE-XRD system, in-situ X-ray reciprocal space mapping during $\operatorname{InGaAs} / \mathrm{GaAs}(100)$ growth has been measured for the first time.

\section{MBE-XRD System \\ MBE (Molecular Beam Epitaxy)-XRD (X-ray Diffraction) \\ @Synchrotron Radiation Facility :SPring-8, Beamline 11XU}
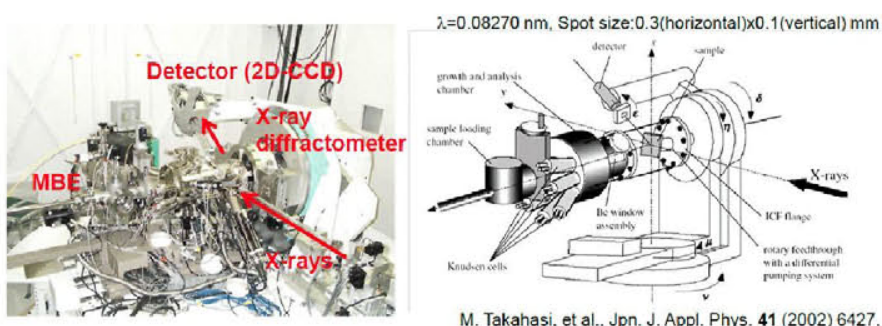

M. Takahasi, et al., Jpn. J. Appl. Phys. 41 (2002) 6427.

- Single laye

- Step graded two layers

- Step graded five layers

- Step graded layers with overshooting layers

Fig. 6. Photograph and schematic illustration of in-situ MBEXRD measurement system at beam-line 11XU of Spring-8.

\section{In situ RSM for single layer}

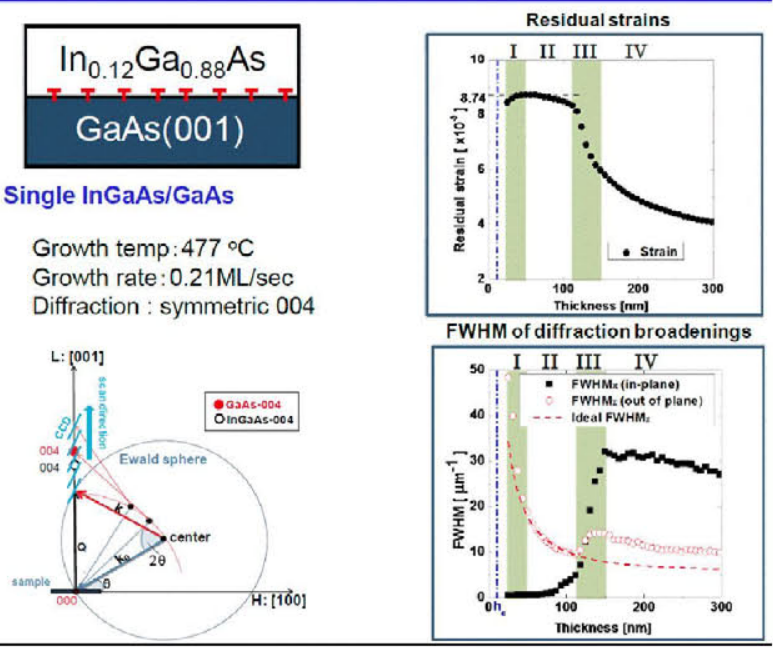

Fig. 7. Film thickness dependence of residual strain and FWHM (full width at half maximum, measure of crystalline quality) determined by in-situ X-ray reciprocal space mapping during InGaAs/GaAs(100) growth.

Fig.ure 7 shows film thickness dependence of residual strain and FWHM (full width at half maximum, measure of crystalline quality) determined by in-situ X-ray reciprocal space mapping during InGaAs/GaAs(100) growth. The dominant dislocation behavior such as (1) gliding of pre- existing threading dislocations, (2) dislocation nucleation and gliding, (3) multiplication of threading dislocations, (4) dislocation annihilation by dislocation coalescence, in each lattice-miss-matched layer has been clarified [10].

Knowledge obtained in this study $[9,10]$ is quite important to design the relaxed buffer layer structures with lower residual strains and lower dislocation densities. Really, worldrecord efficiency inverted epitaxially grown latticemismatched InGaP/GaAs/InGaAs 3-junction cells with efficiencies of $37.9 \%$ under 1 -sun and $43.5 \%$ under $240-305$ suns has been demonstrated by Sharp Co. [8] under this project. Most, recently, $44.4 \%$ efficiency has been achieved with $\mathrm{InGaP} / \mathrm{GaAs} / \mathrm{InGaAs} 3$-junction solar cell under around 300-suns by Sharp. Co. [4].

Figure 8 shows fabrication process of inverted epitaxially grown InGaP/GaAs/InGaAs 3-junction solar cell.

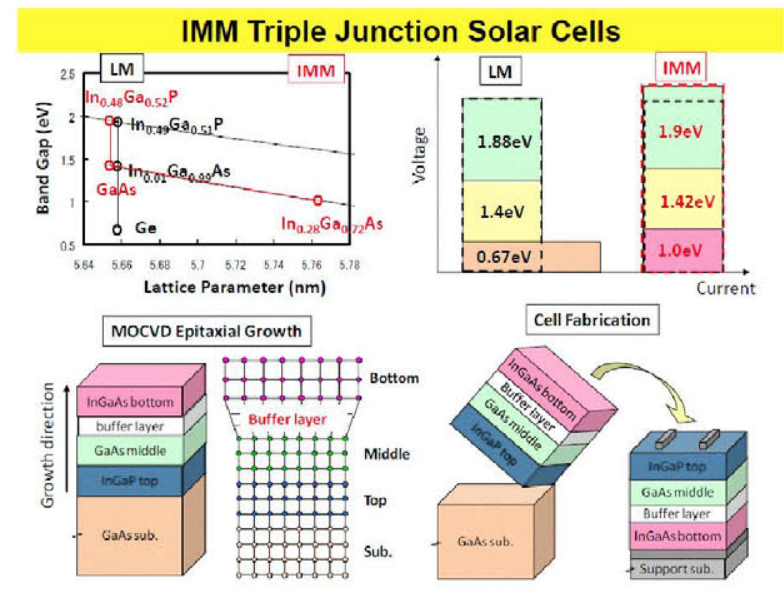

Fig. 8. Fabrication process of inverted epitaxially grown InGaP/GaAs/InGaAs 3-junction solar cell.

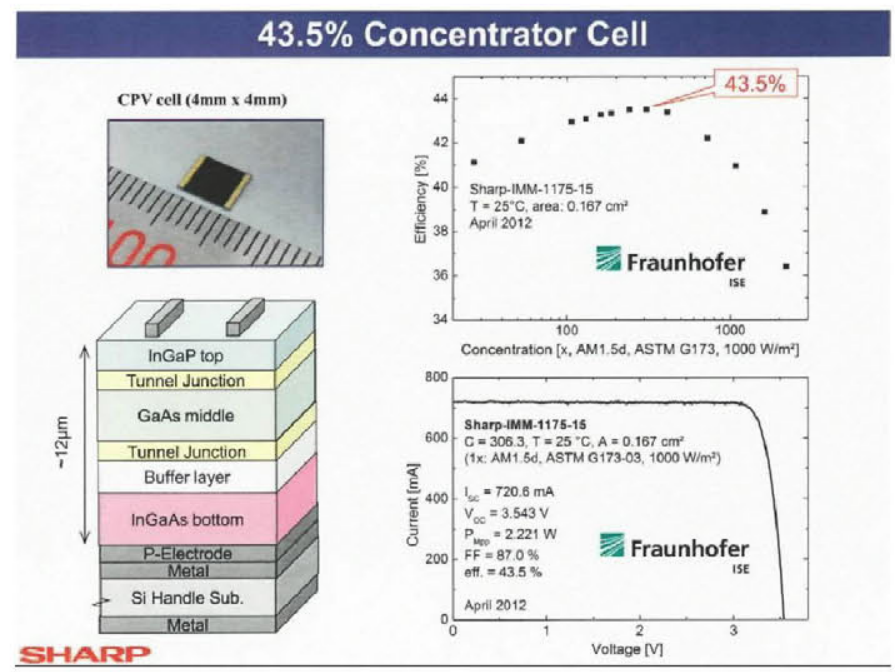

Fig. 9. Structure and $\mathrm{I}-\mathrm{V}$ curve of lattice-mismatched InGaP/GaAs/InGaAs 3-junction solar cell. 
Figure 9 shows structure and I-V curve of latticemismatched InGaP/GaAs/InGaAs 3-junction solar cell achieved by Takamoto et al. [8]. Such efficiencies have been confirmed by AIST and FhG-ISE.

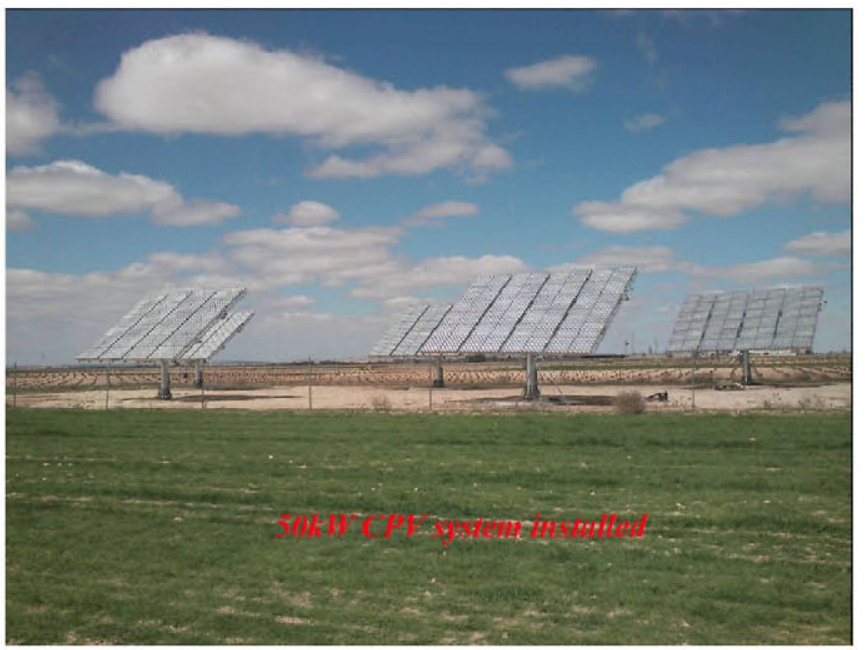

Fig. 10. 50kW CPV system installed neat Toledo in Spain.

Daido Steel Co. [11] has also installed 50kW CPV systems in Spain in cooperation with European partners, as shown in Fig. 10.

In addition, this project also contains fundamental research results such as epitaxial growth and defect analysis of III-V-N materials foe 4-, 5-junction applications, non-radiative recombination phenomena and solar cell properties of quantum-dot (QD) solar cells, round robin measurements of CPV cells and modules by the FhG-ISE and AIST, improvements in performance and reliability of CPV modules.

\section{SUMMARY}

Under the Project of the Europe-Japan Collaborative Research on Concentrator Photovoltaics, world record efficiency (37.9\% under 1-sun) and high-efficiency (43.5\% under $240-306$ suns, most recently $44.4 \%$ under 300 -suns) with inverted epitaxial grown $\mathrm{InGaP} / \mathrm{GaAs} / \mathrm{InGaAs} 3$-junction concentrator solar cells have been achieved.

Concentrator photovoltaics are expected to be one of major high performance, low-cost and highly reliable PV systems because CPV cells have great potential of higher efficiency of more than $50 \%$ as shown in Fig. 11 [2] and lower cost potential [6]..

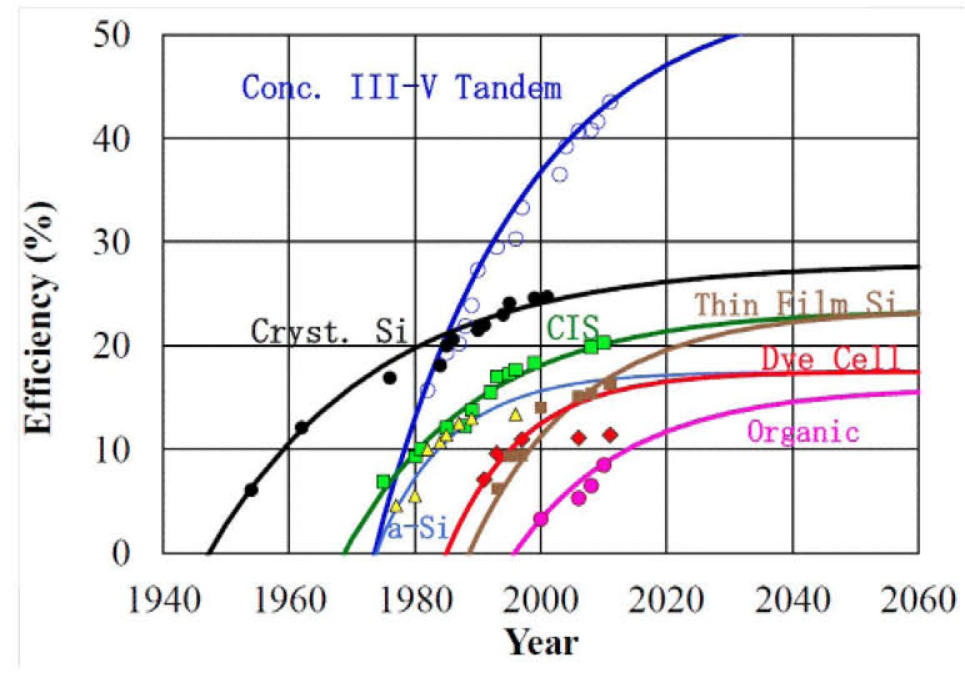

Fig. 11. Efficiency prediction of various solar cells.

\section{ACKNOWLEDGEMENT}

The authors express sincere thanks to EC and NEDO for their financial support and to European and Japanese partners, especially team co-leaders, Prof. Y. Okada, Prof. A. Marti, Prof. N. Kojima, Prof. N. Ekins-Daukes, Dr. A. Bett, Dr. T. Takamoto, Dr. Y. Hishikawa, Dr. G. Siefer, Prof. G. Sala, Dr. K. Araki< Prof. M. Sugiyama, Prof. Y. Nakano and other European and Japanese partners for their fruitful collaboration and discussion.

\section{REFERENCES}

[1] M.A. Green, K. Emery, Y. Hishikawa, W. Warta and D. Dunlop, Progress in Photovoltaics, 21, 1 (2013).

[2] M. Yamaguchi, Proceedings of the 19th European Photovoltaic Solar Energy Conference (2004) p.xl.

[3] V. Sabnis, M. Wiemer and H. Yuen, 9th International Conference on Concentrator Photovoltaic Systems, Miyazaki, Japan, April 15-17, 2013.

[4] T. Takamoto et al., :

[5] M. Yamaguchi and A. Luque, IEEE Trans. ED-46 (10) (1999).

[6] J. Luther, A.W. Bett, B. Burger and F. Dimroth, Proceedings of the $21^{\text {st }}$ European Phtovoltaic Solar Energy Conference (2006) p.2054.

[7] F. Dimroth and S. Kurtz, MRS Bulletin, 32 (3), 230 (2007).

[8] T. Takamoto, $2^{\text {nd }}$ Workshop on Concentrator Photovoltaics, Toyota Tech.Inst., Japan, Nov. 13, 2012.

[9] M. Yamaguchi, K. Nishimura, T. Sasaki, H. Suzuki, K. Arafune, N. Kojima, Y. Ohshita, Y. Okada, A. Yamamoto, T. Takamoto and K. Araki, Solar Energy, 82, 173 (2008).

[10] T. Sasaki, H. Suzuki, M. Takahashi, Y. Ohshita, I. Kamiya and M. Yamaguchi, J. Appl. Phys. 110, 113502 (2011).

[11] K. Araki, $2^{\text {nd }}$ Workshop on Concentrator Photovoltaics, Toyota Tech.Inst., Japan, Nov. $13,2012$. 